\title{
Improving Ways on Japanese Reading Ability
}

\author{
Xiaohong Tang \\ College of Foreign Languages, Bohai University, Jinzhou, 121013, China \\ 251584687@qq.com
}

Keywords: Japanese reading ability; improve ways; intercultural competence; schema theory; new media; five step reading method

\begin{abstract}
Reading ability mainly includes reading abilities, comprehension ability, appreciation ability and transfer application ability. Through reading, can expand the students' knowledge, improve language use ability and information acquisition ability. In view of the current problems, the existence of a single Japanese reading teaching mode, weak knowledge of grammatical structures vocabulary insufficiency, reading efficiency is relatively low and the lack of cross-cultural knowledge, puts forward the effective ways to improve Japanese reading ability. Specific ways include: enlarge vocabulary, system grasp the knowledge of grammar learning; strengthen the cultural background knowledge, cultivate intercultural competence; based on the schema theory, clarify the structure of the article; use the new media, increase extracurricular reading training; master reading skills, promote the five step reading method.
\end{abstract}

\section{Introduction}

Reading ability includes reading abilities, comprehension ability, appreciation ability and transfer application ability, presents a progressive stage, and after the association, and complement each other, form a complete reading ability longitudinal series. Among them, the reading abilities is the perception ability of the written, refers to the cognitive form, reading pronunciation and understanding of meaning, preliminary obtain the ability of the surface meaning of the article. This is not only the most basic ability in the process of reading, but also the basis of the whole process of reading. Understanding ability is the core of the structure of reading ability, including the understanding of words, paragraphs, chapters, writing methods, and the expression of the ideological content. After judgment and reasoning, analysis and synthesis, abstraction and generalization of thinking activities, achieve the understanding of the central idea of the article. Appreciation ability refers to the ability of perception, experience and evaluation of the article, including the content from the content of the article to the form of expression, language, and even the style characteristics and evaluation and appreciation. Must take the correct ideas and healthy aesthetic sentiment as the standard, and constantly improve the standard level in the reading practice, so as to continuously improve the level of appreciation evaluation; migration application ability is the highest level of reading ability, after a lot of reading, the stored knowledge in the reading process in the new ability to make flexible use. In order to obtain new knowledge. Make reading become a kind of beyond the meaning of text construction, make the reading beyond the author's thinking, make the reader's understanding beyond the meaning of the work itself.

Reading is controlled by the reader according to the different purpose, cultivate people's sentiments, improve people's self-cultivation, is actively creating access to information, is a way to cultivate students' ability to obtain information through visual perception of written characters, it is a powerful lever to improve listening, speaking and writing ability, which has an important role in Japanese learning. Language learning is to cultivate the ability of listening, speaking, reading and writing. Among them, listening and reading are the input of language, speaking and writing are the output of language. As an input method of language, reading and listening are equally important. It is an important way to learn and perceive language. Through reading, effectively improve the ability of students to understand and use the language [1]. Not only is the native language, in the foreign language teaching, the reading of the text or extra curricular reading is also important. This paper is aiming at the single teaching mode of Japanese reading, the weak of grammar structure 
knowledge, inadequate reserves of vocabulary knowledge, the low of the reading efficiency and the lack of cross-cultural knowledge, puts forward the effective ways to improve Japanese reading ability.

\section{Expand Vocabulary, Systematic Master Knowledge of Grammar}

The famous linguistician D. A. Wilkins [2] once said: "without grammar, people can't express a lot of things; without vocabulary, people are unable to express anything", This shows the importance of vocabulary in language learning. The vocabulary is connected to form a sentence, and the sentence is connected to form an article. Vocabulary teaching has a direct impact on the quality of foreign language teaching, and it also determines whether students are interested in learning foreign languages. The greater the mastery of vocabulary, the stronger the ability to understand the article, also conducive to the accumulation of student writing materials, and enhance the ability of language use [3]. Japanese is a blend of both the development of multiple text language, only from its etymology, and there are words, Chinese words and foreign words, but also because of the introduction of the country and different age, Japanese vocabulary is relatively large, also produce a lot of synonyms, which increases the difficulty to Japanese learners. In Japanese vocabulary learning process, should grasp the following skills: [4] use sound pronunciation vocabulary; use relationship between superordinate and subordinate words in vocabulary learning; "And language", "Chinese" and "Foreign language" are combined to study; auxiliary word combine before and after collocation as phrase memory; the characteristics of antonyms are used as vocabulary learning.

It is necessary to master the grammar knowledge of the system at the same time to expand vocabulary. Grammar is a branch of linguistics, which studies the use of the word class, the change of word or other means of expression, as well as the function and relation of the word in the sentence, including the word formation, the rule of the configuration and the formation of the group word. Correct grammatical analysis is the basis of reading comprehension. In order to improve the reading ability, we must master the knowledge of grammar. There is an inseparable relationship between grammatical knowledge and reading. In order to understand the meaning of the sentence accurately and quickly understand the meaning of the text, it is necessary to have a solid knowledge of grammar and be able to use it flexibly. For long difficult sentences, we must learn to use the knowledge to understand the grammar, to judge the main part of the sentence, for the modification of the sentence or the complement component can be ignored. Japanese grammar has unique characteristics: rely on auxiliary verb or adhesion to said each word in the sentence function; verbs, adjectives and adjectival verbs and auxiliary verbs have inflected; subject or theme in the first sentence, the predicate in the sentence, the other components in the middle of a sentence; there is no strict order of most components some of the components, can be placed, often can be omitted; has a very complex and important honorific; tone level belongs to the type of tone changes occur between hiragana and katakana. Master these characteristics, the Japanese grammar learning is very helpful.

\section{Strengthen the Cultural Background Knowledge Learning, Cultivate Cross Cultural Competence}

Language is the carrier of culture, learning language and understanding of the relevant cultural background knowledge is complementary to each other. Every nation has its own cultural traditions and customs because of the use of the language. Therefore, when involved in the reading material contains a large number of cultural background, the content of the article is not entirely dependent on the content of the level of language proficiency, and the background knowledge is also inseparable. The background knowledge is the most Japanese's prominent features[5], have a strong group, accustom to obey orders; personal relationship is unbelievable honesty; a perfectionist, obsessed with order; love manual labor; a strong sense of teamwork, preference of family management; open to new things and ideas, but to outsiders hold an attitude of exclusion; ideology is weak, lack of rationalism; strategic thinking, lack of foreign economic policy; basic ethics is the 
importance of shame, and the importance of non crime; special preference, not universal love. Understanding of these characteristics, the reading of the characters on the description of the article is very helpful. Similarly, if you have a background knowledge related to the content of the reading material, can accurately understand the original meaning, but also through the scrutiny, determine the context of the relationship, understand the meaning of the article, more easily understand the theme of the article, and thus receive better learning results.

Neglect of intercultural competence training is also an important reason that leads to the difficulty in improving students' reading ability, which is ignored by the culture relying on the survival of the language [6]. Intercultural competence is a comprehensive ability which includes knowledge, skill, attitude and cultural awareness. Not only includes the external skills and knowledge, but also includes the inner emotion and attitude; not only about the culture and cultural knowledge, skills and attitudes, including the general characteristics of the cultural phenomenon, and the relationship between understanding, insight and evaluation [7]. Any piece of work is based on a certain cultural basis, works is difficult to have the space to survive which deviate from the social cultural. Intercultural competence training not only can make learners succeed in communication with different cultural groups, but also help learners to enhance their understanding ability, thus improve their reading ability.

\section{Use of Schema Theory, Clarify the Structure of the Article}

Schema theory is a theory based on the representation and storage of knowledge organized around a subject. There are a large number of external structural knowledge exist in everyone's brain, schema is a cognitive structure or knowledge structure in memory. Schema is stored in the mind, is from the past experience, is a summary of the situation of the repeated understanding, omittes details and summarizes the common characteristics of some similar situation. Schema theory is good for students to form a good cognitive structure. Cognitive structure is the growth point of new knowledge, and it is the foundation of learning to build up a good cognitive structure. The structure of the article refers to the organization and structure of the article. is the concrete embodiment of the author's writing ideas, including the clue and context, the level and the passage, the transition and the reference, the beginning and the end, etc.. Structure level needs to understand the six types of content [8]: the article clues, writing ideas, the overall structure, the sequence of paragraphs, writing sequence and structural key sentences, etc.. Reading process is the reader's knowledge, that is, the first experience and the article information interaction process, is the process of establishing a link between the existing information schema and the new information.

When Readers read an article, need to mobilize the brain of the schema, and get the new information from the article according to the relevant schema, explain, predict, organize and absorb [9]. In the process of Japanese reading, it is a full use of the schema, grasp the overall knowledge of the structure and framework, improve the ability to control the whole text, deepen the understanding of the content and meaning of the article. For example [10], In "New Japanese Reading Article Select (Book One)" in the "Japanese cultural characteristics", this article is first put forward Japanese conform to the nature of the spirit, and then expounded the spirit reflected in the culture, Japanese is how to use the natural, natural, finally because the Japanese natural beauty itself, so the sense of beauty sublimation. If we sort out the structure of the article, it is very easy to understand the article. In addition, using the schema theory can cultivate the ability of understanding, develop predictive ability and enrich the schema of each teaching link.

\section{Using the New Media, Increase the Extra Curricular Reading Training}

It is difficult to improve students' reading ability comprehensively and effectively depending on the limited reading time in class. Also according to the specific situation of students, there are some plans to guide students to read a certain amount of extra-curricular reading [11]. The reason is: first, the current text teaching contents less, short, can not guarantee the full reading activities; second, intensive reading teaching bears the task of teaching language knowledge, text new words and new 
language structure of high density, not suitable for reading fluency training; third, reading is actually a comprehensive training, a lot of time for to grasp the knowledge points, and listening and speaking, reading and writing exercises, read the special training is not enough. Here said outside reading, let the students read independently, the teacher has planned to carry out extra-curricular reading guidance. Through reading, develop reading skills and methods of students; strengthen basic language knowledge in the text; to broaden their horizons, cultivate students' interest in Japanese literature; through a simplified version of the reading, improve the ability of literature appreciation.

New media is a new form which is different from the traditional media of radio and television, newspapers and magazines, uses digital technology and network technology, through the Internet, broadband LAN, wireless communication network and satellite channels, and computer, mobile phone and digital TV terminal, provide information and entertainment services to users by communication form. The reading of the new media era has the characteristics of openness, diversity, equality, interaction, sharing, and entertainment, and so on [12]. The new media contains a lot of learning materials, students according to their own learning situation, you can download and use [13]. This way of learning, changing the way students learn passively, and promote the students' active learning attitude. Students are usually in the process of reading comprehension, encountered unusual words and long sentences, can be used in the new media translation function to promote the understanding of the word, to provide a convenient way for reading. Improve learning efficiency and reading speed, deepen the memory, is conducive to the improvement of reading ability, thus promoting the improvement of teaching quality. Improving learning efficiency and reading speed, deepen the memory, is conducive to the improvement of reading ability, thus promoting the improvement of teaching quality. New media is no longer subject to the limitations of graphics and text, the computer will expand its ability to process information, the application is also more humane, learning is also gradually increased. The application of new media technology in Japanese reading, improve the teaching methods and adapt to the needs of the current social development.

\section{Master Reading Skills, Promote the Five Step Reading Method}

Master some of the necessary reading skills can improve reading speed. " Discard the false and retain the true, omitted reading", namely grasp the central idea as the main target, words and grammar and skimming center independent; "skip and precision combination", and thought of relatively small sentences to skip, determine the point content carefully weighed [14]

In Japanese in the process of examination of specific reading skills is to ask: the underlined reason and content of the problem, the clue is in before and after the underlined part adjacent; once the negative questions we should pay special attention to, it may be prudent to claim their way of expression of opinion; once the reverse connection, after which the content is very important, may is the ideas and opinions of the author; look at the source before reading an article, understand the theme of this article, to improve the level of understanding; the purpose of reading is to correctly understand the author's ideas and opinions; once the figurative expression, should pay attention to reading the contents of the interpretation of metaphor; repeated words are key words, we must pay special attention to contain the keywords of the content is false statement; judgment problem, to seize the correct incorrect options for false statements; in conjunction to the subject, In the same time, the expression of the same content, which is the core of the author's claim, is the core of the author's claim, and the first thing to do is to make clear the purpose and object of the investigation.

The five step reading method is a popular reading method in countries such as Britain and the United States, it also has some implications for Japanese reading, includes five steps: reading, asking questions, reading, repeating and reviewing the steps. Specific approach is: a comprehensive view. If you read a book, the focus is on the preface, the contents of the summary, the contents of the list, charts, notes and references, etc.. If you read the article, the focus is on the title, the title, the beginning, the end, and the comments. Determine which new knowledge is required to understand and master, in order to determine the key points of reading; set the problem. If the article is abstract, and the conclusion that, skimming. If it is the text, pay attention to the editor's tips and questions, 
and then think about their own should focus on the problem of reading comprehension; in-depth reading. Including reading and thinking. With the problem of reading, focus on key words and key paragraph, make notes and highlighting notation. Contacting with the analysis of reading comprehension problems, both solve difficult problems; recall. Checking the effect of reading through repetition. Finding that the problem is not yet understood and mastered in the repeat, promptly make up for; review. According to the actual situation of reading, using the key review and comprehensive review, the need to memorize the contents must repeatedly memorizing and reciting.

\section{Conclusion}

Reading is not only a means of obtaining information, but also an important form of the improvement of students' quality and the development of cultural undertakings, has a far-reaching influence on the development of students. In the teaching process of Japanese reading, cultivate students' reading ability, improve the students' reading ability in Japanese, cultivate the interest in Japanese reading, improve the cultural connotation of Japanese reading, enable students to get more comprehensive development and lay a solid foundation for the development of the cause.

\section{References}

[1] H. Y. Xiao, "On the choice of reading method in Japanese teaching," Journal of Changchun Education Institute, vol. 31, no. 16, pp. 124-125, 2015.

[2] Online document sharing platform, "The importance of vocabulary in language learning," http://www.doc88.com/p-3307507772304.html, 2016-8-20.

[3] C. L. Cai, "On the importance of English vocabulary in senior high school and its innovative teaching methods," Yushu Wai learning, vol. 29, no. 6, pp. 139-139, 2013.

[4] Y. Q. Chen, "A study of the characteristics and learning techniques of Japanese vocabulary," Straits Science, vol. 28, no. 10, pp. 81-83, 2012.

[5] C. Wang, "Fourteen characteristics of the Japanese," http://blog.ifeng.com/article/6438016.html, 2016-8-20.

[6] L. J. Fan, "Cross cultural competence to improve English reading proficiency," Journal of Liaoning Administration College, vol. 10, no. 2, pp. 149-150, 2008.

[7] Z. Xiang, "Exploration of the Effective Teaching Mode of College Japanese Reading Course," Journal of Anshun University, vol. 17, no. 4, pp. 75-76, 2015.

[8] 360 personal library, "Clarify the level and context of the article," http://www.360doc.com/content/12/0327/19/9338641_198359346.shtml, 2016-8-20.

[9] W. Yang, "Business Japanese text reading based on Schema Theory," Journal of Kaifeng Institute of Education, vol. 36, no. 3, pp. 122-123, 2016.

[10] L. N. Cai, "Application of Schema Theory to Japanese Reading Teaching," Journal of Hunan City University, vol. 33, no. 3, pp. 90-92, 2012.

[11] X. L. Cui, "On the cultivation of students' reading ability in Japanese teaching in higher vocational colleges," Journal of Liaoning Teachers College(Social Sciences Edition), vol. 18, no. 2, pp. 54-55, 2016.

[12] H. Feng, J. Wang, "Brief Analysis of the Reading Features in New Media Reading Times," Journal of Liaoning Agricultural College, vol. 14, no. 1, pp. 63-64, 2012.

[13] L. S. Wang, "Application of network new media technology in English reading teaching in colleges and universities," Western China Quality Education, vol. 1, no. 15, pp. 26-27, 2015.

[14] M. Z. Zhao, "An analysis of the methods to improve the reading ability of Japanese," Knowledge Economy, vol. 17, no. 7, pp. 138-138, 2015.

[15] A. Q. Li, "Brief Tilk on the Five-step Reading Teaching Method of 'Read, Think, Ask and Solve'," Journal of Qingdao Vocational and Technical College, vol. 18, no. 2, pp. 27-29, 2005. 